\title{
16p12.1p12.3 triplication syndrome
}

INSERM

\section{Source}

INSERM. (1999). Orphanet: an online rare disease and orphan drug data base.

16p12.1p12.3 triplication syndrome. ORPHA:485405

16p12.1p12.3 triplication syndrome is a rare chromosomal anomaly syndrome resulting from the partial duplication of the short arm of chromosome 16 characterized by global developmental delay, pre- or post-natal growth delay and distinctive craniofacial features, including short palpebral fissures, epicanthal folds, bulbous nose, thin upper vermillion border, apparently low-set ears and large ear lobes. Variable clinical features that have been reported include congenital heart disease, genitourinary abnormalities, visual anomalies or, less commonly, infantile hepatic disease. Patients are also reported to have tapered fingers. 